\title{
Intervenções musicais: efeitos nas interações com bebês cardiopatas internados em
}

\section{UTI neonatal}

\author{
Musical interventions: effects on interactions with infants with heart disease admitted to the NICU \\ Intervenciones musicales: efectos sobre las interacciones con lactantes con cardiopatías ingresados \\ en la UCIN
}

Fabiana Cozza dos Santos

ORCID: https://orcid.org/0000-0001-8072-7768 Pontifícia Universidade Católica de São Paulo, Brasil E-mail: fabianacozza@gmail.com

Ruth Palladino

ORCID: https://orcid.org/0000-0001-8466-838X Pontifícia Universidade Católica de São Paulo, Brasil E-mail: palladinoruth@ hotmail.com

Caroline Santos Rodrigues da Silva

ORCID: https://orcid.org/0000-0003-1455-4509 Pontifícia Universidade Católica de São Paulo, Brasil

E-mail: carolinesrsilva@gmail.com

Fernanda Prada Machado

ORCID: https://orcid.org/0000-0001-5535-3864 Pontifícia Universidade Católica de São Paulo, Brasil E-mail: fernandapradamachado@gmail.com Maria Claudia Cunha

ORCID: https://orcid.org/0000-0003-3198-6995 Pontifícia Universidade Católica de São Paulo, Brasil E-mail: claudia.cunha1617@gmail.com

\begin{abstract}
Resumo
Objetivo: relatar os efeitos da música cantada na interação com dois bebês cardiopatas precocemente internados em UTI neonatal. Método: estudo descritivo, exploratório, qualitativo, realizado a partir de estudo de 2 casos. Sujeitos: 2 bebês recém-nascidos e suas mães. Ambos os bebês com mesma patologia cardíaca, uma menina e um menino, com intervenções aos 16/23/30 dias de vida e aos 7/14/21 dias de vida, respectivamente. Critérios de seleção: bebês internados em UTI, cujas mães autorizaram a intervenção proposta e assinaram termo de consentimento livre e esclarecido. Local: UTI neonatal de hospital cardiológico de referência em São Paulo. Coleta de dados: Intervenções musicais compostas por três encontros semanais consecutivos (entre outubro e novembro de 2019) de uma cantora, acompanhada por um instrumentista, com os bebês e suas mães. A proposta seguiu uma determinada estrutura (diálogo, improvisação, canções e canção final) e após cada intervenção, foram elaborados diários de campo (ou de bordo) descrevendo os efeitos do canto nos bebês e nas mães, compondo um material de 6 diários. Análise dos dados: Leitura dos diários de bordo para a realização de análise descritiva. Resultados: A partir da proposta de intervenção, foi possível verificar o cuidado e atenção dedicados às várias necessidades sensoriais, físicas e emocionais do bebê e também de seus pais, possibilitando apoio ao processo de criação de vínculo. Verificou-se ainda efeitos nos bebês no que se refere aos padrões de sono, sucção, movimento, além de influência na frequência cardíaca. Conclusão: Foi possível verificar efeitos das intervenções musicais nos dois casos analisados.
\end{abstract}

Palavras-chave: Unidades de Terapia Intensiva Neonatal; Cardiopatias congênitas; Música; Relações mãe-filho.

\begin{abstract}
Aim: to report the effects of singing music on the interaction with two babies with heart disease who were early hospitalized in the NICU. Method: descriptive, exploratory, qualitative study, carried out from a study of 2 cases. Subjects: 2 newborn babies and their mothers. Both babies with the same cardiac pathology, a girl and a boy, with interventions at 16/23/30 days of life and at 7/14/21 days of life, respectively. Selection criteria: babies admitted to the ICU, whose mothers authorized the proposed intervention and signed an informed consent form. Setting: Neonatal ICU of a reference cardiology hospital in São Paulo. Data collection: Musical interventions composed of three consecutive weekly meetings (between October and November 2019) of a singer, accompanied by an instrumentalist, with the babies and their mothers. The proposal followed a certain structure (dialogue, improvisation, songs and final song) and after each intervention, field (or on board) diaries were prepared describing the effects of singing on babies and mothers, composing a material of 6 diaries. Data analysis: Reading the diaries to carry out descriptive analysis.
\end{abstract}


Results: From the intervention proposal, it was possible to verify the care and attention dedicated to the various sensory, physical and emotional needs of the baby and their parents, enabling support for the bonding process. There were also effects on babies with regard to sleep patterns, sucking, movement, in addition to the influence on heart rate. Conclusion: It was possible to verify the effects of musical interventions in the two analyzed cases.

Keywords: Intensive Care Units Neonatal; Heart defects congenital; Music; Mother-child relations.

\section{Resumen}

Objetivo: reportar los efectos de cantar música en la interacción con dos infantes con enfermedad cardíaca que fueron hospitalizados temprano en la UCIN. Método: estudio descriptivo, exploratorio, cualitativo, realizado a partir de un estudio de 2 casos. Sujetos: 2 recién nacidos y sus madres. Ambos bebés con la misma patología cardíaca, una niña y un niño, con intervenciones a los 16/23/30 días de vida y a los 7/14/21 días de vida, respectivamente. Criterios de selección: bebés ingresados en UCI, cuyas madres autorizaron la intervención propuesta y firmaron un consentimiento informado. Lugar: UCI neonatal de un hospital de cardiología de referencia en São Paulo. Recolección de datos: Intervenciones musicales compuestas por tres encuentros semanales consecutivos (entre octubre y noviembre de 2019) de un cantante, acompañado de un instrumentista, con los bebés y sus madres. La propuesta siguió una determinada estructura (diálogo, improvisación, canciones y canto final) y tras cada intervención se elaboraron diarios de campo (o abordo) que describían los efectos del canto en bebés y madres, componiendo un material de 6 diarios. Análisis de datos: lectura de los cuadernos de pesca para realizar análisis descriptivos. Resultados: A partir de la propuesta de intervención se pudo constatar el cuidado y la atención dedicada a las distintas necesidades sensoriales, físicas y emocionales del bebé y sus padres, posibilitando el apoyo al proceso de vinculación. También hubo efectos en los bebés con respecto a los patrones de sueño, la succión, el movimiento, además de la influencia en la frecuencia cardíaca. Conclusión: fue posible verificar los efectos de las intervenciones musicales en los dos casos analizados.

Palabras clave: Unidades de Cuidado Intensivo Neonatal; Cardiopatías congénitas; Música; Relaciones madre-hijo.

\section{Introdução}

Bebês em situação de vulnerabilidade, sobretudo recém-nascidos, requerem especial atenção diante da possibilidade de conturbações no seu desenvolvimento (Baseggio et al., 2017). Mas não apenas esses bebês demandam um olhar cuidadoso, as mães igualmente ocupam um lugar aberto a suscetibilidades e, assim, requerem prudência no trato.

O nascimento do bebê traz à mãe condições físicas (secreção de corticosteroides e diminuição hormonal) e psíquicas (ansiedade, temor, solidão, depressão) inéditas e singulares. Mais ainda, ela é confrontada com uma expectativa inescapável, concernente ao desempenho materno tido como ético, afetivo e responsável que é socialmente estabelecido. Em suma, condições, biopsicosociais, em maior ou menor grau, vão definir possibilidades de vínculos da mãe com seu bebê e, algumas vezes, esta condição delicada em que a mãe é colocada involuntariamente, sofre o incremento de uma novidade impactante: a de seu bebê nascer com alguma doença que implica hospitalização em Unidades de Tratamento Intensivo (UTI) (Battikha et al., 2007; Silva et al., 2020; Battikha et al., 2014; Exequiel et al., 2019; Nazari et al., 2020; Gomes \& Santos, 2020).

Nestes casos, não raramente, a interação mãe-bebê é transtornada, gerando efeitos importantes no desenvolvimento geral da criança e na saúde da mãe e em seu processo de maternagem (Korja, Latva \& Lohtonen, 2012; Nazari et al., 2020; Pilecco \& Backes, 2021). Nesse contexto, mães e bebês constituem grupos de risco (Veronez et al., 2017), reconhecidos e acolhidos por um campo específico da medicina, a neonatologia.

Tendo como público-alvo os recém-nascidos portadores de alguma anomalia e/ou prematuridade que demandam internação em UTI, a neonatologia tem seus primeiros ensaios na França em 1892, com Pierre Budin, que postulou a importância da presença materna como fator importante na recuperação dessas crianças. Tal especialidade médica somente foi reconhecida em 1960, mantendo estreito vínculo com a pediatria e com a obstetrícia, com ênfase no binômio mãe-criança (Marques de Souza et al., 2016).

Contudo, com o avanço tecnológico, especificamente após a incorporação das incubadoras ao ambiente neonatal, no final da década de 1940, desenvolvida por um discípulo de Budin, M. Couney, as mães acabaram excluídas do ambiente dos neonatos, em nome da construção de um espaço controladamente favorável ao tratamento, num explícito controle higienista. A exclusão da figura materna promoveu uma situação tão desfavorável à constituição do vínculo mãe- bebê que algumas delas, 
ao final do tratamento de seus bebês, relutavam em "tê-los de volta" ao lar, provavelmente um efeito negativo da precoce ruptura imposta ao vínculo (Klaus \& Kenel, 1982).

A tecnologia foi protagonista na diminuição da mortalidade infantil, porém as implicações psico-afetivas no isolamento imposto aos bebês pelas UTIs ficaram à margem das abordagens, surgindo a necessidade de alternativas humanizadas que valorizam o vínculo mãe e filho, estreitando os laços (Nazari et al., 2020; Pilecco \& Backes, 2021).

A enfermagem foi pioneira na percepção de que abordagens mais humanistas eram necessárias (Cartaxo et al., 2014) para a proteção dos bebês internados, submetidos constantemente a procedimentos invasivos e dolorosos, além de contarem com a ausência da figura materna, expulsa em nome de controle e previsibilidade nos tratamentos. $\mathrm{O}$ uso do canto, ainda de forma incipiente, surge como opção na lida com esta situação de vulnerabilidade, baseada em pesquisas sobre o comportamento reativo a sons dos bebês recém-nascidos (Biesbroeck et al., 2006).

O retorno das mães (e familiares) ao ambiente das UTI neonatal se deu mais recentemente, a partir de mudanças na formação de profissionais da saúde e, mais uma vez, particularmente dos profissionais da enfermagem, que investiram na maior humanização desse ambiente (Belin et al., 2019). Contudo, até hoje a presença da família na UTI neonatal é assunto de discussão.

No Brasil, foi na década de 70 que as UTI neonatais se intensificaram, inicialmente ainda sem a presença da família. (Tamez e Silva, 2002). Mas, a partir de 2008, como efeito de políticas públicas de humanização do sistema de saúde, se observam novas condutas nessa direção em favor da valorização do vínculo mãe e filho, estreitando esses laços de maneira a minimizar/interromper a evolução de perturbações no desenvolvimento da criança (Cabassu, 2003).

Assim, iniciaram-se as intervenções multidisciplinares focadas no cuidado físico integral. Mais tarde, a dimensão psíquica também foi incluída, numa inspiração trazida pelas teorizações associadas à clínica psicanalítica infantil (Coriat, 1997). Nessa perspectiva, os programas, incluindo especialidades voltadas ao psiquismo, passaram a ser desenvolvidos nos serviços de neonatologia nos principais centros da Europa. Contudo, programas de intervenção na cena familiar mãe/pai-bebê, passam a ser referendados somente em 1994, com a Declaração de Salamanca, quando foi reconhecido o valor do atendimento precoce. São programas constituídos por ações de natureza antecipatória, visando a atenuar ou evitar problemas no desenvolvimento da criança desde tenra idade. (Farias da Costa, 2013),

Feitas essas considerações, importa particularizar o tema do presente artigo, a saber: a introdução da linguagem musical em ambiente de UTI neonatal como recurso fundamental para contornar a vulnerabilidade dos bebês e suas mães.

Nas últimas décadas, abordagens musicais vêm ganhando destaque enquanto instrumento complementar efetivo no tratamento de bebês em risco confinados em UTI neonatal, privilegiando o cuidado individualizado, embalando cada bebê e sua família (Palazzi et al., 2018).

Tal proposta se aproxima da ideia de que mãe e bebê interagem dialogicamente, desde sempre, pela voz (Catão, 2016). Assim, melodia, timbre e ritmo são elementos constituintes do que Malloch e Trevarthen (2009) denominam "musicalidade comunicativa". Importa aqui sublinhar a noção de "diálogo", na medida em que fica suposto que a interação mãe-bebê se assenta num processo simbólico fundamental, o da "antecipação", isto é, a suposição materna de que há diante dela um sujeito falante, um outro que (também) funciona na linguagem (Jerusalinsky, 2004). Antecipação que Catão (2016) aborda e esclarece na instância da voz.

Pesquisas mostram que o recém-nascido prefere o som da voz humana aos ruídos ambientais e, muito precocemente, dá atenção especial à voz de sua mãe, entre outras, sobretudo quando embalada melodicamente (Cohen et al., 2013; SaintGeorges et al., 2013; Silveira et al., 2014).

Em outras palavras: a música gera efeitos na mãe, no bebê e na própria interação entre eles. Para o bebê, há efeitos na regulação das funções vitais, sono e alimentação, maximizando os resultados positivos dos tratamentos (Silva et al.,2013; 
Yakobson, Arnon, Elefant \& Litmanovitz, 2020). Mais ainda, a música pode amenizar os desconfortos da hospitalização, minimizar os efeitos deletérios de procedimentos muito invasivos, com alívio das dores e do incômodo de ruídos durante procedimentos (Silveira et al., 2014; Medina, 2016).

Para a mãe, há redução do estresse e da ansiedade, disponibilizando-a para seus atos relativamente ao seu filho (Vianna et al., 2011; Auto, Amancio, Lanza, 2015). A consequência destes efeitos é o estabelecimento de apego e vínculo, fundamentais para o tratamento e desenvolvimento da criança.

Além disso, salientam-se os resultados de pesquisas que esclarecem que a música "ao vivo" tem mais efeito do que a música gravada, "em particular [..] canções de ninar, músicas preferidas dos pais ou vocalizações improvisadas" (Palazziet al., 2019, p. 3), expondo a importância do compartilhamento (Sá Neto e Rodrigues, 2015), da intersubjetividade, quer dizer, a presença do outro, origem daquela voz, que embala e faz sentido.

As canções de ninar, especificamente, são adequadas pela sua estrutura melódica simples, tom mais graves e ritmo lento. Ademais, quando utilizadas aquelas que têm presença na cultura familiar, o efeito parece mais intenso, pois modulam o cotidiano da família do bebê, trazendo à cena uma intimidade interacional fundamental. Note-se que alguns estudos explicam que a música clássica e sons produzidos por brinquedos musicais, possibilidades apresentadas e utilizadas em muitas pesquisas, não são muito indicados, pois colocariam o bebê em alerta e agitação, exatamente na contramão do que se pretende (Arnon, 2011).

Há programas de intervenção musical desenvolvidos em UTI neonatal, alguns com canções gravadas (Arnon, 2011) e outros ao vivo, com a presença de um cantor/cantora, acompanhado(a) por um(a) instrumentista, que executam músicas variadas (canções de ninar, improvisações musicais e canções que fazem parte do cotidiano familiar do bebê). Em outros, ainda, a mãe canta para seu bebê, entoando qualquer canção à sua escolha (Medeiros, 2018), podendo, inclusive, alternar com a participação de um(a) cantor(a) (Palazzi et al., 2019).

Considerando-se, portanto, que os recém-nascidos são afetados, sobretudo e precocemente, pela voz (Crespin, 2004), calma e melódica, envelopando falas ou cantos cujo enredo representa o que está se passando com ela e em seu entorno (Szejer, 1999) entende-se porque a prática do canto nas intervenções ganhou destaque. Muitas pesquisas são realizadas, visando verificar a efetividade das intervenções musicais tanto nas mães, por meio da aplicação, após as intervenções, de questionários/entrevistas investigando diminuição ou cancelamento da ansiedade/depressão/estresse, quanto nos bebês, por medições de frequência cardíaca e nível de saturação de oxigênio. Algumas pesquisas também miram a percepção das mães sobre os efeitos da intervenção na sua relação com o bebê (Palazzi, 2020)

Isto posto, enuncia-se que o presente estudo emerge de intervenções musicais desenvolvidas em UTI neonatal, com bebês portadores de cardiopatias congênitas em situação de risco, por uma cantora acompanhada de um instrumentista. Seu objetivo é relatar os efeitos da música cantada na interação com dois bebês cardiopatas precocemente internados em UTI neonatal.

\section{Metodologia}

Trata-se de estudo descritivo, exploratório, qualitativo, pois busca identificar os efeitos de um dado fenômeno.

Delineamento: estudo de 2 casos (Yin, 2015)

Local: UTI neonatal de hospital cardiológico de referência em São Paulo

Sujeitos: 2 bebês recém-nascidos e suas mães. Ambos os bebês com mesma patologia cardíaca e recém-nascidos. Uma menina e um menino, com intervenções aos 16/23/30 dias de vida e aos 7/14/21 dias de vida, respectivamente. A menina 
que aqui será chamada de Beatriz*, passou por cirurgia (bem sucedida) entre o primeiro e segundo encontros. O menino, João*, esteve com respiração auxiliar por intubação orotraqueal (IOT) e fototerapia em todos os encontros.

Critérios de seleção: bebês internados em UTI, cujas mães autorizaram a intervenção proposta e assinaram termo de consentimento livre e esclarecido.

Ética: o estudo tem concordância dos participantes e assinatura do termo de consentimento livre e esclarecido. Procedimentos:

Coleta de dados: Intervenções musicais compostas por três encontros semanais consecutivos (entre outubro e novembro de 2019) de uma cantora, acompanhada por um instrumentista, com dois bebês cardiopatas recém-nascidos internados em UTI neonatal e suas mães.

Os encontros ocorreram sempre na mesma estrutura: o par percorria todo o corredor da UTI, em silêncio, e ao final dele, posicionava-se frente a uma díade, em uma baia. A cantora apresentava-se à mãe da criança, explicando sobre a intervenção e pedia-lhe autorização para cantar para o bebê.

Primeiro gesto: conversar com o bebê, utilizando seu nome, destacando sua aparência, pessoas e detalhes do seu entorno. Em seguida, iniciava-se a parte de improvisação vocal e instrumental, aproximando-se de uma canção de ninar. A tonalidade escolhida percorria sempre um pouco mais do que uma oitava, na região médio-grave da cantora (um mezzosoprano), usando como recurso a voz salmodiada, soprosa. Na sequência, o canto, que podia incluir canções de ninar, canções infantis e, para fechamento, a canção "Lugar Comum” (de João Donato \& Gilberto Gil), cuja interpretação traz uma voz salmodiada, com muito ar para efeito de calmaria, emprestando languidez à linha melódica da canção, regulando o timbre à voz maternante (Saint-Georges et al., 2013; Leclère et al. 2014), o que pode resultar numa atmosfera fluida que remeta a ideia de pequenas ondas do mar - presente na canção - tranquilizando o bebê ao buscar reconstituir seu ambiente primário (a água) pelo som.

Após cada intervenção, foram elaborados pela cantora diários de campo (ou de bordo) (Melo de Oliveira et al., 2017), descrevendo os efeitos do canto nos bebês e nas mães, compondo um material de 6 diários.

Importa observar que a cena foi montada, a cada vez, numa mesma estrutura que sustentou a interação, promovendo a "redundância" de que fala Jerusalinsky (2004), ou seja, a permanência da estrutura da cena, e não a mera repetição das coreografias (músicas, por exemplo) que ali se desenvolvem, é ponto que provoca sua efetividade.

Organização e análise de dados: Leitura dos diários de bordo para a realização de análise descritiva, implicando, por vezes, em tópicos explicativos. A análise foi construída por partes concernentes a efeitos idênticos ou distintos entre os casos, sempre representados por excertos dos diários (Yin, 2015), tendo como foco os seguintes momentos estruturais: diálogo, improvisação, canções e canção final.

\section{Resultados e Discussão}

Antes de relatar os efeitos da música cantada na interação com dois bebês cardiopatas internados em UTI neonatal, vale destacar dois pontos fundamentais que orientam todo o trabalho, quais sejam: a noção de redundância que a montagem de estrutura promove e a aposta antecipatória com relação ao bebê de que existe ali um sujeito.

Nessa medida, a montagem da estrutura que se repete e sustenta a interação promovendo a noção de redundância comparece na leitura dos registros: “[..] seguimos o protocolo: primeiramente falar e conversar com a criança; improvisar uma música com sílabas e vogais modulando a voz, prosseguir criando uma canção a partir do nome do bebê e, ao final, interpretar "Lugar Comum". Vale notar, contudo, que a noção de redundância implica, necessariamente dado que é a repetição da

\footnotetext{
* Nomes fictícios para preservar a identidade dos sujeitos
}

${ }^{*}$ Nomes fictícios para preservar a identidade dos sujeitos 
diferença, no desenvolvimento particular da interação, ainda que haja uma estrutura que responda a expectativas teóricas, quais sejam: diálogo, improvisação, canto intimista, canto final, como se pode ler em: "quando, já na canção Lugar Comum, subi para o registro mais agudo na segunda parte da canção (a água bateu, o vento soprou...), alongava a testa e sustentava o movimento da minha voz, quase na duração da nota e de minha expiração.

Importa verificar ainda que há uma aposta antecipatória com relação ao bebê, sempre considerado um interlocutor, independentemente da sua condição fisiológica: "o bebê manteve um sono profundo durante todo o nosso encontro. Mesmo assim, seguimos o protocolo: primeiramente falar e conversar com a criança; improvisar uma música com sílabas e vogais modulando a voz, prosseguir criando uma canção a partir do nome do bebê e, ao final, interpretar "Lugar Comum", de João Donato e Gilberto Gil".

As cenas propostas realçam ao menos duas das postulações teóricas que sustentam as intervenções desta natureza. Apontam para o fato de que 1) o que afeta é a voz cantada, fonte de canto e encanto que encapsula simbolicamente o bebê (Catão, 2016) e 2) as palavras, elas mesmas afetam o bebê, envelopadas em determinadas entonações que encenam um diálogo e que, igualmente, o encapsulam (Saint-Georges et al., 2013; Cohen et al., 2013; Bourvis et al., 2017).

Uma palavra fundamental no campo intersubjetivo é o nome da criança e por esse motivo, uma das etapas da intervenção proposta incluiu esse aspecto. Isto porque a intervenção da demanda do outro não deve ser anônima, mas subjetivamente composta e nem se dirigir a um corpo anônimo, mas a um sujeito (Leite, 2008). Isso é fundamental para que o projeto de antecipação do adulto tenha efeito, pois a criança precisa se reconhecer sujeito e isto acontece porque é nomeado. $\mathrm{O}$ campo intersubjetivo é construído na e pela linguagem. $\mathrm{O}$ adulto se refere desde sempre ao bebê enquanto um sujeito falante e, assim, a cena é sempre dialógica: o adulto fala com a criança, conversa com ela, "como se ", anunciando-a, antecipando-a como sujeito. Este é um projeto antecipatório que vai sustentar o desenvolvimento da criança, principalmente no caso dos bebês em situação de vulnerabilidade (Jerusalinsky, 2004).

Trazendo o nome da criança, ficou impossibilitado que os ditos ali havidos, embalados por melodias, ficassem anônimos, perdessem valor. O nome da criança, ao ganhar lugar na cena, revela o reconhecimento de sua presença na posição de outro, posição em um espaço simbólico, e que é a ela que os afetos são dirigidos, como se pode ver no registro a seguir:

"aos primeiros minutos do canto, Beatriz reagiu sugando ininterruptamente, como se estivesse mamando. Aos poucos (após quatro minutos de improvisos com sílabas e vogais) eu trouxe o nome "Beatriz" para dentro da canção criando um pequeno enredo improvisado: oi Beatriz! A titia veio cantar para você/o papai e a mamãe estão aqui/que lindeza de menina é você”. Os pais, num leve sorriso labial, foram ficando mais relaxados, como se a música lhes acalmasse também e os movimentos da filha fossem a expiração subtraída que lhes permitia desmontarem os corpos tensos e cansados. Beatriz, ao ouvir seu nome, intercalava o sugar com pequenos alongamentos de perna e braço, vitalizando-se, ao que sua mãe lhe retribuía com carinhos nos pés e olhares - de pai e mãe - ternos, amorosos".

O mesmo efeito no semblante da mãe, se percebe no recorte da cena com João:

-“nossa João, como você gosta de música! Parece até que estou dançando, tia! Percebi o semblante da mãe mudando, mais envolvida, emocionada, com a tensão sendo subtraída naqueles breves 15 minutos de música".

Em suma, o posicionamento da cantora enquanto interlocutora, sustentado por certa perspectiva conceitual, traz à cena a suposição de um sujeito, ainda que não haja significantes para sustentar uma interpretação (como o bebê em sono profundo, provavelmente em estado pós-cirúrgico, ou chorando porque inundado de dor), mas com insistência na interlocução, pelo canto que embala e captura a criança, pelas palavras que compõem uma coreografia dialógica e, finalmente, por referir-se e convocar a criança pelo seu nome próprio, tanto nos diálogos quanto nas canções, reconhecendo-a, de fato, sujeito e não um corpo 
anônimo: "sentia sua irritação no choro que queria explodir, mas continha-se espaçadamente (como se soluçasse), numa respiração alta (de peito), nos movimentos das mãozinhas e bracinhos trêmulos de irritação. Comecei dizendo que entendia a sua irritação e que, de fato, já estava muito chato ficar ali. Mas que o lacinho na cabeça era uma lindeza, feito ela e que eu ia cantar para acalmá-la. Após estas primeiras palavras inclinei-me sobre o berço e comecei seguindo a mesma sequência das duas intervenções anteriores. Pedi ao violonista que ficasse do outro lado do berço, mais próximo do que o habitual, dado o barulho das máquinas e o número grande de pessoas na UTI Pediátrica. A gaze ao redor de toda a cabeça também era um empecilho à audição, possivelmente diminuindo sua percepção e atenção à música. Após algumas repetições da cadência (harmônica, ou seja, sequência de acordes) Beatriz abriu os olhos em direção a mim fixamente. Seu choro foi espaçando enquanto erguia os bracinhos para cima numa força que ainda não tinha visto".

Nesses trechos é possível verificar o cuidado e atenção dedicados às várias necessidades sensoriais, físicas e emocionais do bebê e também de seus pais, possibilitando um apoio ao processo de criação de vínculo, assim como apontam Yakobson et al. (2020) em estudo sobre os efeitos da musicoterapia nos sinais vitais, sono e alimentação em bebês prematuros em UTIs neonatais.

Iniciar a intervenção com um "diálogo", referindo-se à criança pelo seu nome próprio, reconhecendo, inclusive seu estado de vulnerabilidade, é decisão que emoldura simbolicamente a cena, quer dizer, a configura enquanto plenamente intersubjetiva, o que empodera o bebê e, na consequência, sua mãe.

No segundo momento da intervenção eram os improvisos, que, quase sempre, iniciavam a cantoria, como se a intenção fosse capturar a criança, no embalo melódico, confirmando-a na estrutura intersubjetiva, dado que é tomada enquanto sujeito, fato anunciado em momentos de diálogo, já exemplificados.

"comecei a intervenção musical vocalizando livremente em cima da harmonia em tonalidade maior (E) ao lado do violonista".

"aos primeiros minutos do canto, Beatriz reagiu sugando ininterruptamente, como se estivesse mamando. Aos poucos (após quatro minutos de improvisos com sílabas e vogais) eu trouxe o nome de Beatriz para dentro da canção criando um pequeno enredo improvisado.

Vale notar que a literatura descreve a sucção não nutritiva também como um dos desfechos esperados em intervenções dessa natureza com bebês prematuros (Loewy et al., 2013; Yakobson, Arnon et al., 2020).

Para consolidar a interação, os momentos de canto propriamente ditos: no encanto da voz (Catão, 2016; Palazzi, et al., 2018)

"comecei a cantar e, feito vara de condão, logo nos primeiros acordes, João reagiu franzindo a testa como se o som lhe soprasse o rosto, lhe garantindo uma energia tal que, mesmo de olhos fechados, seu corpo reagia"

"após algumas repetições da cadência (harmônica, ou seja, sequência de acordes) Beatriz abriu os olhos em direção a mim fixamente. Seu choro foi espaçando enquanto erguia os bracinhos para cima numa força que ainda não tinha visto. Segui o canto dedicando-o essencialmente a ela, confesso que surpresa, tamanho propósito corporal, concentração do olhar e interação desta pequena bebê com a música, com uma voz".

A cantora relata que ia modulando a cantoria, mudando a música, aumentando ou diminuindo o volume, a melodia, o timbre, numa busca de interação, ou seja, circuito de palavra, melodia e afeto, tencionando colocar a criança na posição de sujeito, reconhecida sua condição de vulnerabilidade:

"improvisando inicialmente com sílabas para mantê-la descansando (estava dormindo) mas logo introduzindo o nome de Beatriz em pequenas frases, com Beatriz se movimentando. Ao final, cantei Lugar Comum (João Donato e 
Gilberto Gil), ao que me pareceu que Beatriz descobriu, nas canções dos poetas um bom "lugar comum" (para si e para os pais) e um novo "começo do caminhar pra beira de outro lugar". Dormiu profundamente".

Vai, também, movimentando-se no espaço, buscando criar cenas interacionais, marcadas discursiva e corporalmente:

"pedi licença à mãe para me apoiar em seu joelho para que minha voz pudesse ser audível à Beatriz que estava com respirador e muitos eletrodos monitorando sua frequência cardíaca. A ação também visava uma aproximação - maior contato - com a mãe que não expressou simpatia ou crédito à essa atividade, tamanha tensão corporal estampada no rosto jovem, assustado e envelhecido da dor".

Este exemplo põe à mostra, também e inclusive, a busca da cantora por criar uma interação na qual a mãe, os pais, sempre têm participação, apontando para uma efetividade da intervenção na condição dos pais (Vianna et al., 2011).

E, mais ainda, põe à mostra os efeitos que batem e rebatem em todos:

"Beatriz, ao ouvir seu nome, intercalava o sugar com pequenos alongamentos de perna e braço, vitalizando-se, ao que sua mãe lhe retribuía com carinhos nos pés e olhares - de pai e mãe - ternos, amorosos".

Sobre os momentos de canto trazendo quietude e acolhimento à criança:

"após algumas repetições da cadência (harmônica) Beatriz abriu os olhos em direção a mim fixamente. Seu choro foi espaçando enquanto erguia os bracinhos para cima numa força que ainda não tinha visto. Segui o canto dedicando-o essencialmente a ela, confesso que surpresa, tamanho propósito corporal, concentração do olhar e interação desta pequena bebê com a música, com uma voz".

"quando canto "a água bateu, o vento soprou", permite-se até tirar uma soneca"

"quando, já na canção Lugar Comum, subi para o registro mais agudo na segunda parte da canção (a água bateu, o vento soprou...), alongava a testa e sustentava o movimento da minha voz, quase na duração da nota e de minha expiração. Feito um maestro que mantém o som da orquestra com o gesto largo e a baqueta suspensa. Se esforçou e abriu os olhos algumas vezes ao longo de nossa intervenção. Ao final, quando terminamos a visita, reclamou franzindo a testa, ao que entendi que nos pedia um "bis". Prosseguimos por mais alguns minutos nos despedindo de João cantando suavemente "beira do mar/lugar comum/começo do caminhar/pra beira de outro lugar" e trazendo sons percussivos com a boca e o violão (chiados e batidinhas no bojo do instrumento). João entendeu e concordou com a despedida, agradecido e adormecendo".

Neste momento, ficam completamente evidentes efeitos nos bebês que adormecem, se movimentam, olham para cantora, fazem expressões faciais. Efeitos esses que a literatura na área aponta como possibilidades de desfechos secundários observados em procedimentos dessa natureza com bebês em UTIs neonatais, ao lado dos sinais vitais e alimentação (Loewy et al., 2013; Yakobson, Arnon et al., 2020).

"a frequência cardíaca de Beatriz era altíssima (ela ainda aguardava a data da cirurgia). Porém, a música proporcionou momentos calmos, onde a respiração ficou menos aflita".

"se esforçou e abriu os olhos algumas vezes ao longo de nossa intervenção. Ao final, quando terminamos a visita, reclamou franzindo a testa, ao que entendi que nos pedia um "bis". 
Cria-se, assim, o circuito palavra/canto/afeto entre todos e, por que não dizer, entre todos mesmo, ali inserida a mãe e, por vezes, o pai. Parece que o canto e as palavras da cantora capturam também a mãe, que consegue dirigir seu olhar à criança. Assim, os efeitos se espalham no bebê, na mãe e na díade mãe-bebê. Ex:

"os pais, num leve sorriso labial, foram ficando mais relaxados, como se a música lhes acalmasse também e os movimentos da filha fossem a expiração subtraída que lhes permitia desmontarem os corpos tensos e cansados. Beatriz, ao ouvir seu nome, intercalava o sugar com pequenos alongamentos de perna e braço, vitalizando-se, ao que sua mãe lhe retribuía com carinhos nos pés e olhares - de pai e mãe - ternos, amorosos".

-"Nossa João, como você gosta de música! Parece até que estou dançando, tia! Percebi o semblante da mãe mudando, mais envolvida, emocionada, com a tensão sendo subtraída naqueles breves 15 minutos de música".

\section{Conclusão}

O presente estudo relata os efeitos da música cantada na interação com dois bebês cardiopatas precocemente internados em UTI neonatal a partir de uma estrutura de intervenção especificamente montada. Os efeitos observados nos dois casos vão desde modificação nos padrões de choro, sucção, períodos de alerta, sono, e até efeitos na relação dos pais com os bebês.

Sugere-se que outros estudos sejam feitos com um número maior de sujeitos de forma a verificar e sistematizar os resultados obtidos com esse tipo de intervenção musical.

\section{Agradecimentos}

O presente trabalho foi realizado com apoio da Coordenação de Aperfeiçoamento de Pessoal de Nível Superior Brasil (CAPES).

\section{Referências}

Arnon, S. (2011). Music therapy intervention in the neonatal intensive care unity environment. Jornal de Pediatria, 87(3), 183-5. https://dx.doi.org/10.1590/S0021-755720111000300001

Auto, F. M. L., Amancio, O. M. S. \& Lanza F. C. (2015). Efeito da música sobre o ganho de peso de prematuros maiores de 32 semanas: ensaio clínico randomizado. Revista Paulista de Pediatria, 31(3), e293-9.

Baseggio, D. B., Dias, M. P. D., Brusque, S. R. \& Donelli, T. M. S. \& Mendes, P. (2017). Vivências de mães e bebês prematuros durante a internação neonatal. Revista Temas em Psicologia, 25(1), 153-167. http://dx.org/10.9788/TP2017.1-10

Battikha, E. C., Correa de Faria, M. C. \& Kopelman, B. I. (2007). As representações maternas acerca do bebê que nasce com doenças orgânicas graves. Rev. Psicologia: Teoria e Pesquisa, 23, 17-24.

Battikha, E. C., M. de Carvalho, M. T. \& Kopelman, B. I. (2014). A formação do neonatologista e os paradigmas implicados na relação com os pais na Unidade de Terapia Intensiva Neonatal. Revista Paulista de Pediatria, 32(1), 11-6.

Belin, C. H. S, Valerão, N.B., Viegel de Ávila, A. T., Silveira dos Santos, C.S. \& Rovedder, P. M. E. (2019). O cuidado centrado na família em um serviço de neonatologia: relato de experiência de uma equipe multiprofissional. Clin biomed Res, 39, 308.

Biesbroeck, F. C. C., Cardim, M. G. \& Nascimento, M. A. L. (2006). A resposta fisiológica do recém nato à percepção sonora: quando cantar é uma forma de cuidar em enfermagem em uma UTI neonatal. Revista Soc Bras Enferm Ped., 6(2), 85-8.

Bourvis, N., Singer, M., Saint-Georges, C., Bodeau, N., Chetouani. M., Cohen, D. \& Feldman, R. (2018). Pre-linguistic infants employ complex communicative loops to engage mothers in social exchanges and repair interaction ruptures. R. Soc. open sci., 5(1), 170274170274 . http://doi.org/10.1098/rsos.170274

Cabassu, G. (2003). Palavras em torno do berço. In: Wanderley, D. B. (Org.), Palavras em torno do berço (pp. 21-32). Ágalma Editora.

Cartaxo, L. S., et al.., (2014). Vivência de mães na unidade de terapia intensiva neonatal. Rev. enferm. UERJ. 22(4), $551-7$.

Catão, I. (2016). O corpo como resposta à invocação da mãe. Revista Psicologia, Diversidade e Saúde. 4(1), https://doi.org/10.17267/2317-3394rpds.v4i1.665 
Cohen, D., Cassel, R. S., Saint-Georges, C., Mahdhaoui, A., Laznik, M-C., Apicella, F., et al. (2013). Do parentese prosody and fathers' involvement in interacting facilitate social interaction in infants who later develop autism? PLoS ONE, 8(5), e61402. 10.1371/journal.pone.0061402

Coriat, E. (1997). Psicanálise e clínica de bebês. Artes e Ofícios Ed.

Crespin, G. (2004). A clínica precoce: o nascimento do humano. São Paulo: Casa do Psicólogo.

Exequiel, N. P., Milbrath, V. M., Gabatz, R. I. B., Vaz, J. C., Hirschmann, B., Hirschmann, R. (2019). Vivências da família do neonato internado em unidade de terapia intensiva. Revista de Enfermagem Atual In Derme, 89(27). https://doi.org/10.31011/reaid-2019-v.89-n.27-art.466

Farias da Costa, R. C. G. (2013). O estado de conhecimento sobre estimulação precoce no conjunto de teses e dissertações brasileiras no período entre 2000 e 2011. [Dissertação de Mestrado, Programa de Pós-Graduação em Educação, UFPR].

Gomes, T. R. A. \& Santos, A. F. de O. (2020). A relação mãe-bebê prematuro na UTI neonatal: Um olhar Winnicottiano. Revista Eletrônica Acervo Saúde, 12(2), e2422-7.

Jerusalinsky, A. (2004). Psicanálise e desenvolvimento infantil. Artes e Ofícios.

Klaus, M. H. \& Kennell, J. H. (1982). Parent-infant bonding. Mosby CollegePress.

Korja, R., Latva, R. \& Lehtonen, L. (2012). The effects of preterm 632 birth on mother-infant interaction and attachment during 633 the infant's first two years. Acta Obstet Gynecol Scand. 91(2), 164-73.

Leclère, C., Viaux, S., Avril, M., Achard, C., Chetouani, M., et al. (2014) Why Synchrony Matters during Mother-Child Interactions: A Systematic Review. PLOS ONE, 9(12), e113571. https://doi.org/10.1371/journal.pone.0113571

Leite, C. A. O. (2008). Quando o corpo pede um nome. [Tese de doutorado, Instituto de Estudos da Linguagem, UNICAMP].

Loewy, J., Stewart, K., Dassler, A. M., Telsey, A. \& Homel P. (2013). The effects of Music Therapy on Vital Signs, Feeding and sleep in premature Infants. Pediatrics, 131(5), 902-18. https://doi.org/10.1542/peds.2012-1367

Malloch, S. \& Trevarthen, C. (org). (2009). Communicative musicality. Exploring the basis of human companionship. Oxford University Press, Oxford UK.

Marques de Souza, M. S., Vieira, L. N., Carvalho, S. B. \& Lima Monte, N. (2016). Os cuidados de enfermagem com os recém-nascidos na UTI. Revista Saúde (em foco), 3(1), 94-106.

Medeiros, M. M. (2018). Musicoterapia e a interação mãe-bebê pré-termo na UTI neonatal: evidências de um estudo de caso. XXX Salão de Iniciação Científica, UFRGS.

Medina, I. M. F. (2016). Efectividad de la musicoterapia em la réduccion de las apneas del prematuro. Nuberos Científica, 2 (16), 60-4.

Melo de Oliveira, A., Gerevini, A.M. \& Strohschoen, A. G. (2017). Diário de Bordo: uma ferramenta metodológica para o desenvolvimento de uma alfabetização científica. Revista tempos e Espaços em Educação, 10(22), 119-132. https://doi: 10.20952/revtee.v10i22.6429.

Nazari, R., Moradi Koosha, F., Rezaie, S., Akbari, N., Qolizadeh, A. \& Sabzi, Z. (2020). Experiences of the mothers of infants hospitalized in the neonatal intensive care unit (NICU). J Neonatal Perinatal Med., 13(4), 571-9. https://:10.3233/NPM-190205.

Palazzi, A., Meschini, R. \& Piccinini, C. A. (2019). Intervenção musicoterápica para mãe-bebê pré-termo: uma proposta de intervenção em UTI neonatal. Revista Psicologia em Estudo, 24, e41123. https://doi.org/10.4025/psicolestud.v24i0.41123

Palazzi, A., Nunes, C. C. \& Piccinini, C. A. (2018). Music therapy intervention for the mother-preterm infant dyad: evidence from a case study in a brazilian NICU. Voices: A world forum for music therapy. 17(2), https://doi.org/10.15845/voices.v17i2.916

Palazzi, A. (2020). Musicoterapia na UTI Neonatal: contribuições para saúde mental materna, respostas fisiológicas do bebê pré-termo e interação mãebebê. [Tese de doutorado, UFRGS].

Pilecco, J. C. \& Backes, D. S. (2020). Mother-baby binding in a Neonatal Intensive Care Unit: Interactive Care Technology. Research, Society and Development, 9(8), e198985610. https://doi.org/10.33448/rsd-v9i8.5610

Sá Neto, J. A. \& Rodrigues, B. M. R. D. (2015). A ação intencional da equipe de enfermagem ao cuidar do RN na UTI neonatal. Ciência, Cuidado e Saúde, 14(3), 1237-44. https://doi.org/10.4025/cienccuidsaude.v14i3.22320

Saint-Georges, C., Chetouani, M., Cassel, R., Apicella, F., Mahdhaoui, A., Muratori, F., Laznik, M-C. \& Cohen D. (2013). Motherese in interaction: at the cross-road of emotion and cognition? (A systematic review). PLoS ONE 8(10), e78103. https://doi.org/10.1371/journal.pone.0078103

Silva, C. M., Cação, M. R., Silva, K. C., Marques, C. F. \& Merey L. S. (2013). Respostas fisiológicas de recém-nascidos pré-termo submetidos à musicoterapia clássica. Revista Paulista de Pediatria, 31(1), 30-6.

Silva, J. M. Q., Almeida, M. S., Coelho, E. A. C., Ferraz dos Anjos, K., Borges, T. P. \& Fernandes de Medeiros, I. (2020). Aprendizados e cuidados de mães no método canguru. Revista Baiana de Enfermagem, 34, 1-1. https://doi.org/10.18471/rbe.v34.36994

Silveira, W., Samagaio, S., Pereira, N., Cerqueira, P., Miranda, D. \& Loureiro, C. (2014). O efeito da musicoterapia na alteração nos estados de alerta do prematuro. In: Dreher S. \& Mayer G. (orgs). A clínica na musicoterapia: avanços e perspectivas (p.139-52). São Leopoldo: EST.

Szejer, M. (1999). Palavras para nascer: A Escuta Psicanalítica na Maternidade. Casa do Psicólogo.

Tamez, R. \& Silva, M. (2002). Enfermagem na UTI neonatal: assistência ao recém-nascido de alto risco. Guanabara Koogan. 
Research, Society and Development, v. 10, n. 16, e349101623861, 2021

(CC BY 4.0) | ISSN 2525-3409 | DOI: http://dx.doi.org/10.33448/rsd-v10i16.23861

Veronez, M., Borghesan, N. A. B., Correa, D. A. M. \& Harumi, I. (2017). Vivência de mães de bebês prematuros do nascimento à alta: notas de diários de campo. Revista Gaúcha de Enfermagem, 38(2), e60911. https://doi.org/10.1590/1983-1447.2017.02.60911

Vianna, M. N. S., Arnaldo, P., Carvalhaes, A. S. \& Cunha, A. J. L. A. (2011). Music theraphy may increase breastfeeding rates among mothers of premature newborns: a randomized controlled trial. Jornal de Pediatria, 87(3), 206-12.

Yakobson, D., Arnon, S., Gold, C., Elefant, C., Litmanovitz, I. \& Beck, B. D. (2020). Music Therapy for Preterm Infants and Their Parents: A Cluster-

Randomized Controlled Trial Protocol. J Music Ther. 57(2), 219-42. https://doi.org/10.1093/jmt/thaa002

Yin, R. K. (2010). Pesquisa qualitativa do início ao fim. Ed. Penso. 